\title{
Assessment of solar reflectance of roofing assemblies of dwellings in Guayaquil, Ecuador
}

\author{
J. Macias ${ }^{1,2}$, G. Soriano ${ }^{2}$, H. Sanchez ${ }^{2} \&$ Y. Canchingre ${ }^{2}$ \\ ${ }^{1}$ Instituto Nacional de Eficiencia Energética y Energías Renovables, \\ INER, Ecuador \\ ${ }^{2}$ Centro de Energías Renovables y Alternativas, CERA, \\ Escuela Superior Politécnica del Litoral, ESPOL, Ecuador
}

\begin{abstract}
A study of the impact of solar reflectance of roofing assemblies on energy behaviour of social interest dwellings located in Guayaquil, Ecuador is presented. Values of solar reflectivity were obtained for a typical sample of local roofing materials using the procedure for measuring the solar reflectance of flat or curved roofing assemblies developed by Akabari, which is suitable for assemblies and surface materials with surface irregularities and non-homogeneous colour. This methodology when compared with the standard methodology ASTM E1918 "Standard Test Method for Measuring Solar Reflectance of Horizontal and LowSloped Surfaces in the Field" produces differences of \pm 0.02 units of reflectance for sample assemblies of homogenous colour and \pm 0.03 units in sample assemblies of heterogeneous colour. Values in the range of 0.29 to 0.51 were measured from the sample of local materials. The social interest dwelling model follows the guidelines of the Ecuadorian Secretary of Housing. The energy behaviour of the dwelling was modelled using a simulation software compliant with ANSI/ASHRAE 140. Differences of the annual energy consumption in KW-h of the dwelling when using a standard window air conditioning unit are analysed for the range of measured and ideal solar reflectance values. Thermal comfort is studied by a floating simulation to obtain the effect of solar reflectance on maximum interior temperature and relative humidity.

Keywords: solar reflectance, roofing assembly, energy consumption, thermal comfort.
\end{abstract}




\section{Introduction}

Performance of building envelope is a significant issue during a building life cycle. Several researchers and engineering practitioners have suggested that solar absorption of envelope surfaces plays an important role, and recommending high reflectance roofs for warm and hot climates due to its potential of energy savings up to $20 \%$ due cooling load decrease [1]. Synnefa et al. [2] provide a review which validates high reflectance surfaces as effective means to improve envelope energy performance, and shows that increasing of roof solar reflectance can reduce 18$93 \%$ of cooling loads and peak cooling demand HVAC by $11-27 \%$.

Additionally, in locations with high solar irradiance $\left(1000 \mathrm{~W} / \mathrm{m}^{2}\right)$ and low wind speed conditions, the temperature of a black opaque surface with a solar reflectance $(\mathrm{SR}=0.05)$ of 0.05 could reach around $50^{\circ} \mathrm{C}$ higher than ambient air temperature. On the other hand, white low reflectance surface $(\mathrm{SR}=0.8)$ the temperature rises about $10^{\circ} \mathrm{C}$ at the same conditions [2]. Finally, the application of high reflectance roofing compliance credits for international buildings codes such as ASHRAE 90.1 and 90.2, and it is an inexpensive and effective approach to contribute to buildings energy efficiency [3-5].

At the local level, the Ecuadorian government through the Secretaries of Housing aims to develop guidelines for sustainable social interest dwellings through the program SAV-BID [6]. The guidelines propose the use of native improved materials and friendly environmental designs at low cost. A complete energy assessment of the proposed guidelines have not been performed.

Guayaquil is Ecuador's largest city with a population of 2 million people and it is located at $2^{\circ} 16^{\prime} 51^{\prime \prime}$ South and $79^{\circ} 54^{\prime} 49^{\prime \prime}$ West. Guayaquil's weather is tropical with average temperature of $27^{\circ} \mathrm{C}$ [7]. In consequence, cooling energy demand is relative high and therefore roof reflectance plays a key role in order to reach comfort temperatures in dwellings.

The objective of this work is to measure solar reflectance of typical roof assemblies and evaluate how it affects the cooling energy demand for dwellings in Guayaquil. The material's reflectance were calculated using an experimental method developed by Akbari et al. [3] and the performance of a social dwelling model under different roofing conditions was simulated and compared.

\section{Methodology}

Six different roofing materials samples of typical use in Guayaquil were collected. Their experimental solar reflectance (SR) was quantified by Akbari's experimental procedure. Next, these results supported an energy simulation of a typical social interest dwelling. Finally, variations in annual cooling demands, peak cooling rates and hours of discomfort were analysed.

There are some experimental methods to calculate spectral solar reflectance on surfaces. Standard ASTM E903 employs a spectrophotometer with an integrating sphere, a method appropriate for laboratory environment and controlled conditions [8]. This procedure requires flat and smooth samples with dimensions of $100 \times$ $100 \mathrm{~mm}$, with homogeneous colour and composition. 
Alternatively, standard test method ASTM C1549 utilizes a portable reflectometer adequate for field and laboratory conditions. The portable reflectometer accuracy is within \pm 0.003 units of the spectrophotometer technique [9]. Reflectometers as spectrometers need homogeneous and smooth surfaces with a minimal sample area requirement of $5 \mathrm{~cm}^{2}$. It is possible to measure curved surfaces, with radius larger than $5 \mathrm{~cm}$.

For field measurements, standard ASTM E1918 is the most appropriate. A precision pyranometer measures irradiance at different conditions. Solar reflectance is determined using a ratio of irradiances. The method is applicable for heterogeneous and irregular surfaces, such as low and high profile tile assemblies [10]. Nevertheless, it presents some difficulties such as mounting assemblies of $10 \mathrm{~m}^{2}$ at least, and taking measurements on clear sunny conditions without clouds and haze.

In addition, Akbari et al. [3] proposed a modification on the procedure of standard ASTM E1918 with the name of E1918A. The procedure E1918A employs samples of $1 \mathrm{~m}^{2}$ and two reference surfaces (black and white). Akbari determined solar reflectance of 14 clay and concrete tiles samples via E1918, E1918A and E903. The results from procedure E1918A differ from the other standard methods by values of \pm 0.02 and \pm 0.03 units of reflectance for homogenous and heterogeneous colour samples respectively.

In order to determine solar reflectance of roofing assemblies, procedure E1918A was selected due to its experimental simplicity and low cost. Four different samples representative of roofing assemblies in Guayaquil were characterized. Figure 1 provides a schematic of the experimental setup where the target solar reflectance $S R_{t}$ is calculated with equation (1), where $R_{w}$ and $R_{b}$ are known reflectance values of the white and black reference surfaces respectively. $I_{1}, I_{2}$ and $I_{3}$ are the values of the reflected irradiance from the white surface, black surface and roofing assembly acquired from the pyranometer as established by Akbari et al. [3].

$$
S R_{t}=R_{b}+\frac{I_{3}-I_{2}}{I_{1}-I_{2}}\left(R_{w}-R_{b}\right)
$$

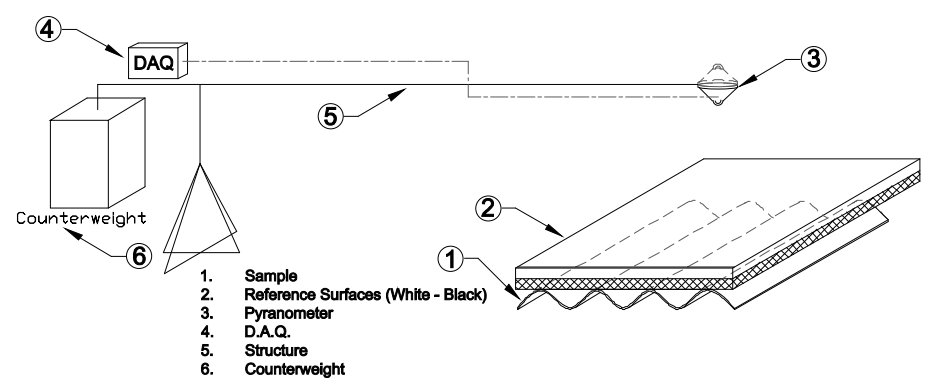

Figure 1: $\quad$ Schematic for the experimental Akbari method [3]. 
Figure 2 shows the tested set of common roofing assemblies. It comprises of samples of red ceramic tile, steel panel, zinc and fiber cement. The values were obtained between June and August 2014, because it is the period with the most uniform solar irradiance in Guayaquil.

The impact of variation of solar reflectance was assessed with an energy simulation of a house under Guayaquil's weather using Energy Plus [11]. Table 1 presents climatic conditions of Guayaquil for a typical meteorological year. The weather in Guayaquil could be classified as hot and humid type 1A according to ASHRAE 90.1 definitions. In a typical year, the global solar insolation of Guayaquil is $1825 \mathrm{kWh} / \mathrm{m}^{2}$-year, [7]. Meteorological data were generated from METEONORM database [12].

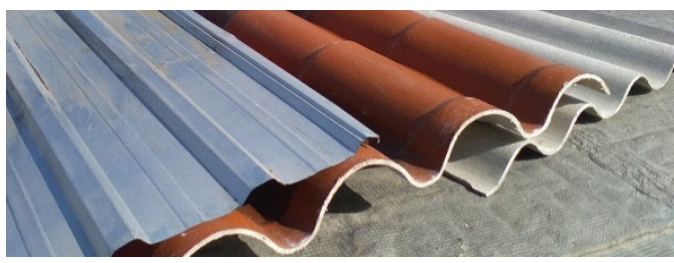

Figure 2: $\quad$ Samples of typical roofing used on Ecuadorian dwellings.

The model simulates a social interest dwelling constructed with a low sloped roof a single story with $42 \mathrm{~m}^{2}$ of area, height is $2.7 \mathrm{~m}$ (as seen in figure 3 ). Table 2 provides $\mathrm{U}$ values $\left(\mathrm{W} / \mathrm{m}^{2} \mathrm{~K}\right)$ for envelope surfaces in the model. Its fenestration area is $2 \mathrm{~m}^{2}$ and the model has a unique exterior door.

Heat inputs were set for a low profile occupation, lighting of $11.84 \mathrm{~W} / \mathrm{m}^{2}$ for lighting and $5.81 \mathrm{~W} / \mathrm{m}^{2}$ by miscellaneous equipment. Every external surface has an emittance of 0.9 , and the thermostat set point for the cooling system was set to $23^{\circ} \mathrm{C}$.

Table 1: Climatic conditions of a typical meteorological year in Guayaquil, Ecuador [12].

\begin{tabular}{|c|c|c|c|c|c|c|c|}
\hline \multirow{2}{*}{ Month } & \multicolumn{3}{|c|}{ Dry Bulb } & \multicolumn{3}{c|}{ \%RH } & $\begin{array}{c}\text { Average } \\
\text { Dew Point } \\
\end{array}$ \\
\cline { 2 - 7 } & Max. & Min. & Aveg. & Max. & Min. & Aveg. & $\left({ }^{\circ} \mathbf{C}\right)$ \\
\hline Jan & 33.4 & 21.2 & 26.3 & 100 & 34 & 69 & 19.8 \\
\hline Feb & 31.9 & 20.9 & 26.0 & 100 & 45 & 76 & 21.2 \\
\hline Mar & 32.5 & 21.6 & 26.3 & 98 & 49 & 77 & 21.7 \\
\hline Apr & 32.5 & 21.8 & 26.2 & 100 & 45 & 74 & 21.0 \\
\hline May & 32.8 & 21.2 & 25.7 & 100 & 40 & 72 & 20.0 \\
\hline Jun & 30.2 & 19.0 & 23.9 & 98 & 45 & 74 & 18.6 \\
\hline Jul & 30.1 & 18.2 & 23.7 & 99 & 48 & 72 & 18.1 \\
\hline Aug & 29.7 & 18.7 & 23.5 & 100 & 45 & 71 & 17.8 \\
\hline Sept & 30.0 & 18.4 & 23.5 & 97 & 42 & 71 & 17.7 \\
\hline Oct & 31.2 & 19.3 & 24.0 & 96 & 39 & 70 & 17.9 \\
\hline Nov & 31.5 & 19.2 & 24.2 & 100 & 41 & 69 & 17.8 \\
\hline Dec & 32.3 & 20.8 & 26.1 & 97 & 38 & 64 & 18.5 \\
\hline
\end{tabular}



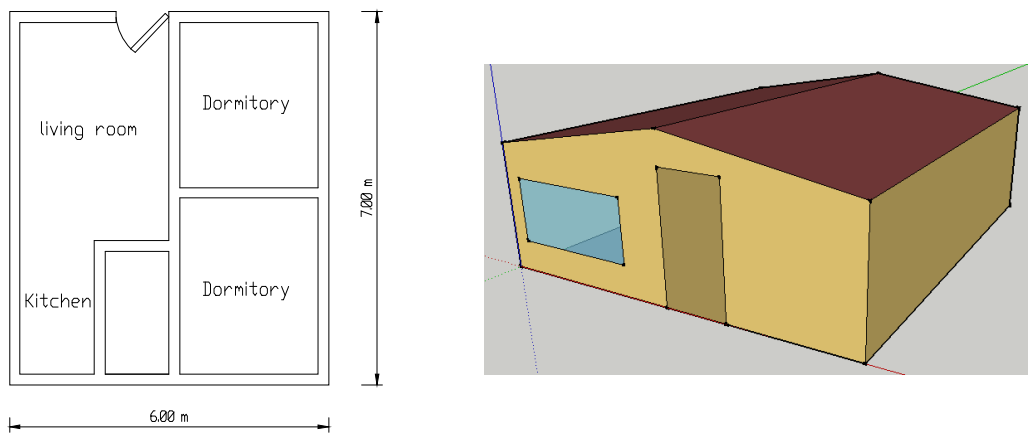

Figure 3: Top view of a social dwelling model.

Table 2: $\quad$ U values for envelope conditions applied in the model.

\begin{tabular}{|l|c|}
\hline \multicolumn{1}{|c|}{ Envelope surface } & $\mathrm{U}\left(\mathrm{W} / \mathrm{m}^{2} \mathrm{~K}\right)$ \\
\hline Walls & 0.86 \\
\hline Floor & 3.15 \\
\hline Roof & 7.28 \\
\hline Door & 1.18 \\
\hline Window & 5.83 \\
\hline
\end{tabular}

Changes on annual cooling energy consumption, peak cooling rates and average zone air temperature serve as the performance metric of the different roofing assemblies. The model was set for every value of solar reflectance measured as well as three reference values: opaque reference $\mathrm{SR}=0.15$, moderate high reflectance $\mathrm{SR}=0.60$, and high reflectance reference $\mathrm{SR}=0.80$.

\section{Results}

Table 3 presents the solar reflectance values obtained with procedure E1918A. Results evidence that largest solar reflectance value is from the steel panel sample, while ceramic tiles sample is the smallest.

Next, results from Energy Plus simulations reflect the energy performance from each case (as shown in Figure 4). This figure shows a difference of $15.70 \%$ of annual cooling demand between a red ceramic tile and steel panel. Also a maximum decrease of $19.31 \%$ in September between the two materials is found.

Figure 4 displays results of the annual cooling demand and peak cooling rates at varying solar reflectance value. Annual cooling consumption falls as solar reflectance increases, with a maximum change of $-43.88 \%$ match to $\mathrm{SR}=0.8$ surface with respect to $\mathrm{SR}=0.15$. A difference of $-15.70 \%$ of cooling demand between the red tile and steel panel samples was identified. 
Table 3: Reflectance values of pieces tested.

\begin{tabular}{|l|l|}
\hline \multicolumn{1}{|c|}{ Sample } & $S R_{t}$ \\
\hline Steel panel & 0.51 \\
\hline Zinc panel & 0.42 \\
\hline Fiber cement & 0.32 \\
\hline Red Ceramic Tile & 0.29 \\
\hline
\end{tabular}

Also, a maximum decrease of $-40.21 \%$ for peak cooling rates was observed between limiting values of solar reflectance. While a difference of $-14.19 \%$ corresponds to red tile and steel panel samples.

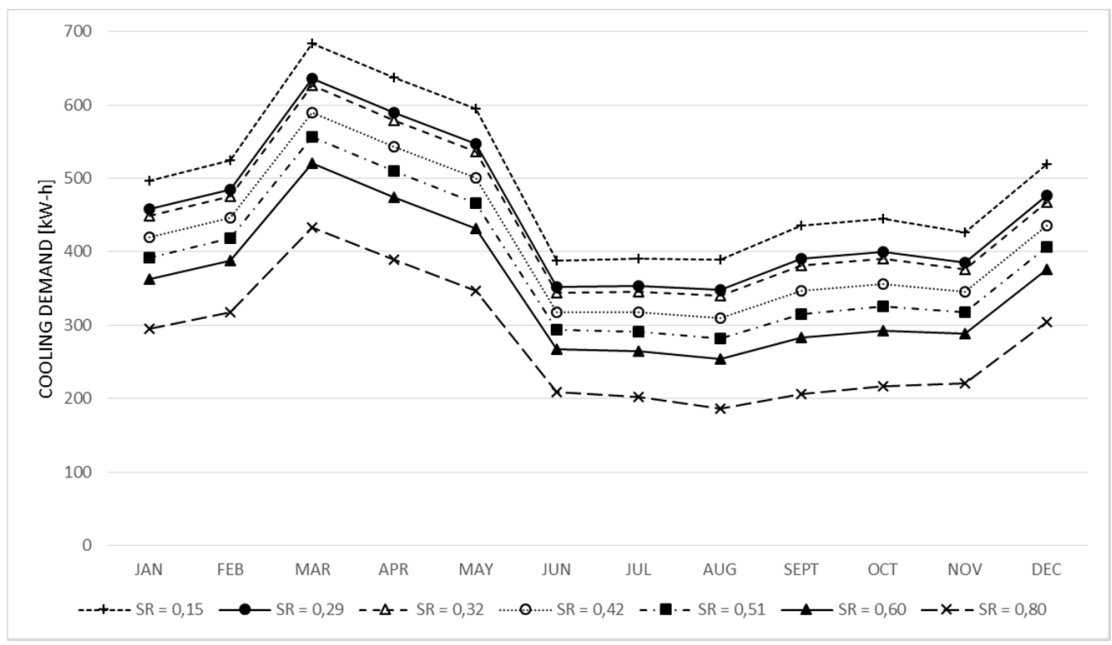

Figure 4: Monthly electric consumption for roofing with different reflectance values.

Table 4 indicates the total annual hours of uncomfortable air temperatures indoors following guidelines of ASHRAE 55 [13]. Results reveal a minor decrease for solar reflectance values up to 0.51 . For larger solar reflectances values of 0.6 and 0.8 , the reduction of non-comfortable hours is significant.

\section{Discussion}

Synnefa et al. [2], suggest that employment of high solar reflectance roofing yields positive effects in thermal building performance, especially at hot climates, even cities with moderate cooling loads showed improved performance.

The hot and humid climate in Guayaquil makes employment of high reflectance roofs appropriate. This paper illustrates the effects on cooling loads and electricity consumption with different solar reflectance values on roofs. Cooling load reduction of the vicinity of $20 \%$ could be achieved by changing red ceramic tiles for steel panels. However, changing reflectance of roofing assembly exhibits 


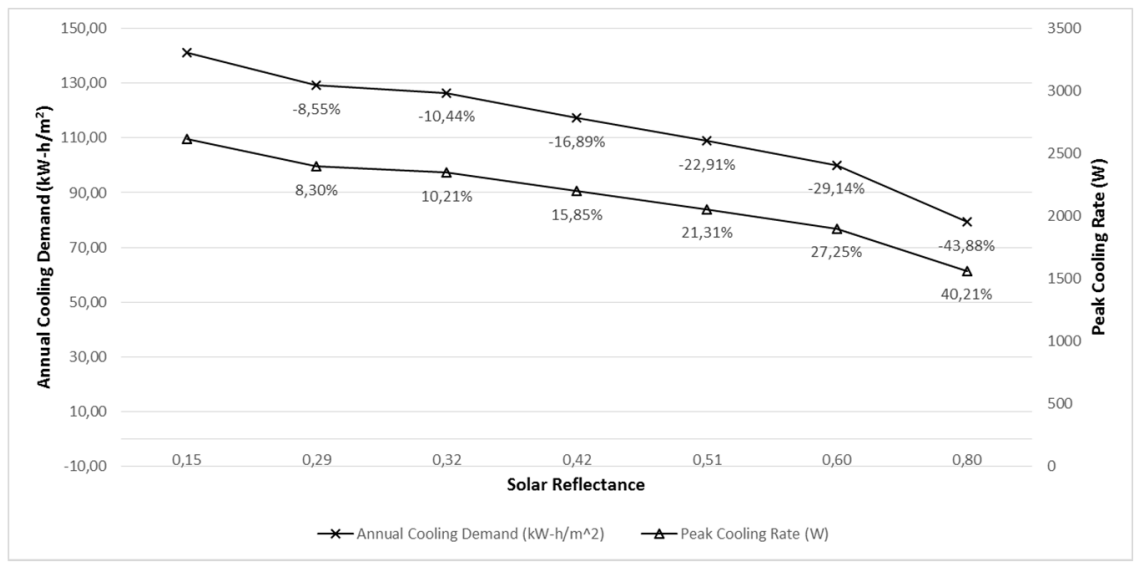

Figure 5: Annual cooling demand and peak cooling rates versus solar reflectance of roofing.

Table 4: Annual hours of uncomfortable temperature.

\begin{tabular}{|c|c|c|}
\hline $\mathbf{S R}$ & $\begin{array}{c}\text { Not Comfortable time for air } \\
\text { temperature [ASHRAE 55] } \\
\text { (HOURS/YEAR) }\end{array}$ & Reduction (\%) \\
\hline $\mathbf{0 , 1 5}$ & 2899 & \\
\hline $\mathbf{0 , 2 9}$ & 2871 & $0,95 \%$ \\
\hline $\mathbf{0 , 3 2}$ & 2862 & $1,28 \%$ \\
\hline $\mathbf{0 , 4 2}$ & 2825 & $2,54 \%$ \\
\hline $\mathbf{0 , 5 1}$ & 2765 & $4,61 \%$ \\
\hline $\mathbf{0 , 6 0}$ & 2689 & $7,24 \%$ \\
\hline $\mathbf{0 , 8 0}$ & 2313 & $20,22 \%$ \\
\hline
\end{tabular}

almost no effect on uncomfortable hours inside the dwelling when not using a mechanical cooling system.

It is worth noting that samples used in this project were new and clean. Factors such as aging as well as dust were not considered in the project. Synnefa et al. [2] advise regular cleaning of roofing assemblies to avoid reduction on solar reflectance. Bretz and Akbari [14] provide a study of the effects of aging in solar reflectance of assemblies, with reductions of up to 0.15 mostly within the first year.

\section{Conclusions}

Via procedure E1918A, solar reflectance of four typical roof samples in Guayaquil was calculated. This low cost method allows getting reliable experimental data at a lower cost when comparing with traditional procedures such as ASTM E903, ASTM C1549 and ASTM E1918. Solar reflectance varied from 0.29 to 0.51, with the best results from the steel panel assembly. 
Energy simulation shows a significant decrease of cooling loads, peak cooling rate with an increase in solar reflectance. It is possible to decrease $15.70 \%$ of annual cooling demand and a maximum reduction monthly of $19.31 \%$ by switching red ceramic tile with steel panel while maintaining a constant thermal resistivity on the assembly. Besides, for extreme reference values of solar reflectance in the range 0.15 and 0.80 , it would be possible to achieve annual energy savings of $61.98 \mathrm{kWh} / \mathrm{m}^{2}$ or $43.88 \%$.

For peak cooling rates, a maximum reduction of $40.21 \%$ with a solar reflectance of 0.8 with a baseline SR of 0.15 is possible. A difference of $14.19 \%$ between a red tile and steel panel were found.

\section{References}

[1] American Society of Heating, Refrigerating and Air-Condtioning Engineers, Inc., in ASHRAE GreenGuide, The Design, Construction, and Operation of Sustainable Buildings, 2010, pp. 89-102.

[2] A. Synnefa, M. Santamouris and H. Akbari, "Estimating the effect of using cool coatings on energy loads and thermal comfort in residential buildings in various climatic conditions," 2007.

[3] H. Akbari, R. Levinson and S. Stern, "Procedure for measuring the solar reflectance of flat or curved roofing assemblies," ScienceDirect, vol. 82, pp. 648-655, 2008.

[4] American Society of Heating, Refrigerating and Air-Conditioning Engineers, Inc, ASHRAE 90.1 Energy Standard for Buildings except LowRise Residential Buildings, Atlanta, 2010.

[5] American Society of Heating, Refrigerating and Air-Conditioning Engineers, Inc, ASHRAE 90.2 Energy-Efficient Design of Low-Rise Residential Buildings, Atlanta, 2007.

[6] Centro Ecuatoriano de Derecho Ambiental CEDA, "Hacia una matriz energética diversificada en Ecuador," Quito, 2011.

[7] Consejo Nacional de Electricidad CONELEC, Atlas Solar del Ecuador con Fines de generación eléctrica, 2008.

[8] American Society Testing Materials, ASTM E903 Standard Test Method for Solar Absortance, Reflectance, and Transmittance of Materials Using Integrating Spheres, 2012.

[9] American Society Testing Materials, ASTM C1549 Standard Test Method for Determination of Solar Reflectance Near Ambient Temperature Using a Portable Solar Reflectometer, 2009.

[10] American Society Testing Materials, “ASTM E1918 Standard Test Method for Measuring Solar Reflectance of Horizontal and Low-Sloped Surfaces in the Field," 2006.

[11] U.S. Department of Energy, www.eere.energy.gov/buildings/energyplus/, 2015. [Online]. Available: http://apps1.eere.energy.gov/buildings /energyplus. [Accessed 2015]. 
[12] Swiss Federal Institute of Technology., METEONORM, Global Meteorological Database for Solar Energy and Applied Climatology, Zurich, Switzerland.

[13] ASHRAE, "Standard 55-1992, Thermal Environmental Conditions for Human Occupancy".

[14] S. Bretz and H. Akbari, "Long-term performance of high albedo roof coatings," Energy and Buildings, no. 25, pp. 159-167, 1997. 